\title{
Evaluating the role of scrum methodology for risk management in information technology enterprises
}

\author{
Ahmed Muayad Younus ${ }^{1}{ }^{*}(\mathbb{D}$, Mohanad Abumandil 2 \\ ${ }^{1}$ Postgraduate Centre, (PGC), LUTC University, Cyberjaya, Malaysia \\ ${ }^{2}$ Management, Faculty of Business, UNISZA University, Iklan jawatan kosong, Malaysia
}

\begin{tabular}{|c|c|c|c|}
\hline Received: 01.03 .2021 & Accepted: 12.05 .2021 & Published: 30.06 .2021 & Final Version: 30.06 .2021 \\
\hline
\end{tabular}

\begin{abstract}
This study aims to evaluating the Scrum methodology's effectiveness in risk management techniques in Oman, Iraq, and Qatar. Businesses in Oman, Iraq, and Qatar discuss management in terms of the scale of their operations and the influence of risk management has on the success of information technology efforts. This research focuses on information technology firms and technical projects. Investigated them to get a full comprehension of the underlying premises of the postulation. Risk management as a technique is fraught with peril. This makes determining if risk management is an appropriate strategy for managing and managing risks in the IT manufacturing process difficult. The study shows how the Scrum framework is used to execute risk management in IT organizations. Quantitative research was used to collect data for this study. The sample consists of 150 employees from different IT businesses. Collecting data via the use of standardized tools (questionnaires). The researcher conducted an online survey using Google Forms. The aim of this research is to determine the influence of the scrum approach to risk management in enterprises (information technology projects).to achieve higher performance and more efficient energy management. Implement innovative risk management tactics based on technology. Findings The data show that most employees are adjusting to the new scrum management strategy they have used at work, with the majority reporting feeling at ease with the new system. (53, ,56 percent are signatures, 70 , percent) Adopt the scrum method throughout the project's life cycle. Technology adoption in the workplace to adapt to rapid changes in energy management systems and varied government laws encouraging energy saving. Employee training and flexibility in dealing with programs that have the potential to disrupt the process assist achieving the goals. Restructuring projects firms to optimize their energy and overall performance.
\end{abstract}

Keywords: Scrum methodology, influence of risk management, IT businesses, Evaluating

\section{Introduction}

Scrum, methodology, Scrum is an iterative and methodical method for project management that is structured around an "inspect and change" philosophy. Scrum is used to spread the software in intervals called "Sprints" (usually 3-6-week iterations). [3] A sprint starts with planning and concludes with evaluation. A sprint preparation meeting is a time-restricted conference call dedicated to developing a detailed sprint calendar. Project partners attend sprint assessment meetings to assess the company, the industry, and technology. A retrospective meeting may be scheduled to examine completed sprints. A daily Scrum meeting is a brief daily meeting (often up to 15 minutes long) during which each team member must answer three questions: What did I do yesterday? What am I going to accomplish today, and how will I overcome the obstacles that stand in my way? It created

\footnotetext{
* Corresponding Author: eng.ahmed.muayad@gmail.com
} 
three components: product backlogs, sprint backlogs, and burn down charts. Backlogs comprise company-specific criteria, while normal burn down maps depict the remaining work. The risk of using Scrum in global application development: they often considered Scrum beneficial for colocated projects with small team sizes. Scrum teams are self-organizing and are built on collaboration and coordination amongst diverse teams. However, project shareholders' allocation to initiatives is also diversified by physical, geographical, and sociocultural differences [4]. It creates a slew of complications or threats that might stymie cooperative and collaborative operations. Such project structural elements as coordination, increased number of sites, engagement of many project personnel, and lack of tool support may all have a significant impact on a project's interaction mechanisms. However, we would argue that individual project concerns would introduce several impediments or hazards that would obstruct the usage of Scrum. By gaining a grasp of the project's context, you may begin practicing Scrum. Examine: The goal of the published analysis was to identify and appraise the issues or risks that must be considered while implementing Scrum in projects, as well as supplementary approaches for mitigating these risks, as documented in the academic literature. We conducted a Comprehensive Literature Review to categorize the key articles addressing the use of Scrum, which involved a variety of tasks, including the development of a review procedure, the identification and collection of primary documents, data analysis and synthesis, and documentation of the findings [3] [4]. Ours specified twenty main studies that examine the utilization of Scrum activities. You will discover a comprehensive summary of our observations, including all of them. To mitigate these risks, we assess the primary issues or hazards as well as supplementary measures. Our findings are organized logically, as any realistic observation is expected to do. Denotes: Research Issues. Is there a correlation between the success of information technology projects and risk management? " To provide a complete answer to the research question, this research aim establishes the objectives for this study, which are to investigate the risk management strategy in the Scrum context often employed in information technology projects. My interpretative study aims to elucidate the risk management process in a Scrum environment Provide a feasible solution by using the scrum methodology. The following are the specific objectives of the problem:

$>$ Rapid implementation of high-quality tasks in a timely way

$>$ Resolving logistical and organizational issues for the team. From developers and project managers.

$>$ Modification of the working style to a more contemporary appearance.

\section{Literature Review}

A. Scrum development and project management to provide critical consistency in an oftencomplicated project delivery strategy, the Scrum organization defines tasks, responsibilities, and meetings. Scrum is well-known for its fast-paced Sprints, during which they deliver an MVP every two weeks [4]. The Kanban method: By visualizing their workflow, limiting work in progress (WIP), and enhancing the flow of backlogged items, Kanban enables more traditional businesses to improve their operations. [5] Kanban is the Japanese phrase for "visual sign" or "note." Extreme Programming (XP): XP emphasizes application quality and adaptability to changing client expectations. Pair programming, comprehensive code updates, and unit testing characterize this Scrum method. Adaptive System Development (ASD): ASD is most recognized for its repeated three-phase development phase. FDD is a lightweight Scrum approach that blends a variety of industry best 
practices into a five-step implementation cycle. The development cycle generates the overall idea, the timetable by feature, the idea by feature, and the build by feature [5] [6] [7].

B. Risks in performing Projects and the Scrum Framework Mode of Team Coordination For projects with minimal risk or ambiguity, they offer an impersonal coordination mode; for projects with moderate levels of uncertainty, it offered a personal coordination mode; and for projects with elevated levels of uncertainty, a group coordination mode is recommended. [14] External and internal integration, organized planning, and institutional oversight in terms of the intrinsic risk of a project, which is affected by the project's scale, technological expertise, and layout, several types of projects require distinct management resources to implement risk management countermeasures. [14] For low project risk or confusion, use arm's length relationships between parties involved.

\section{Methodology}

The researcher will use a descriptive research design and will collect data from various government and business institutions that use a work-from-home plan for human resource management. There are 150 people that responded to an online survey. Questionnaire for a survey created using Google forms and the researcher will use a quantitative approach [6] [7] [10][22]. A technique for tabulating and interpreting the data. Conclusions and Discussion What Are the Benefits of scrum method to risk Management?

The researcher has distributed to Enterprises As a consequence, the population research is segmented by firm and total staff count of 150 at (Oman, Iraq, and Qatar), (Table.1)

Table 1. Respondent Numbers of Employees in different countries

\begin{tabular}{|c|c|c|}
\hline NO. & Country of Employees & Respondent Number \\
\hline 1. & Oman & 30 \\
\hline 2. & Iraq & 75 \\
\hline 3. & Qatar & 45 \\
\hline 4. & Total & 150 \\
\hline
\end{tabular}

In this analysis, the frequency distribution was used to determine the characteristics of the respondent profile. In relation to the current study, data was gathered from 150 respondents. Have been asked about demographic information: here are gender, age, ethnicity, and current study. (Table.2)

Table 2. Demographics' Result

\begin{tabular}{lll}
\hline Demographic & Items & No. of Respondents \\
\hline Gander & Male & 120 \\
Age & Female & 30 \\
& $20-28$ & 100 \\
Experiences of years & $20-45$ & 50 \\
& $1-20$ & 110 \\
Current Academic study & $1-5$ & 40 \\
& Diploma & 20 \\
& Bachelor's degree & 100 \\
& Master's degree & 30 \\
\hline
\end{tabular}




\section{Result}

In Figure 1, the diagram depicts the primary benefit of using the scrum model in small and mediumsized business firms, which is risk reduction during development. 56.1 percent believe that establishing a scrum model will assist the company and teams in completing the project successfully. It is used by Scrum teams to structure their product development efforts. A scrum master manages the team's overall process, while developers and product owners collaborate with the business to understand requirements. Managing medium and small scrum teams can help reduce meeting time and boost productivity. In these instances, the team may wish to consider adopting a scrum methodology. This technique subdivides larger scrum project teams into smaller scrum project subteams. Additionally, some believe that implementing the scrum model in a business can accelerate development by 12.1 percent in terms of organization and management.

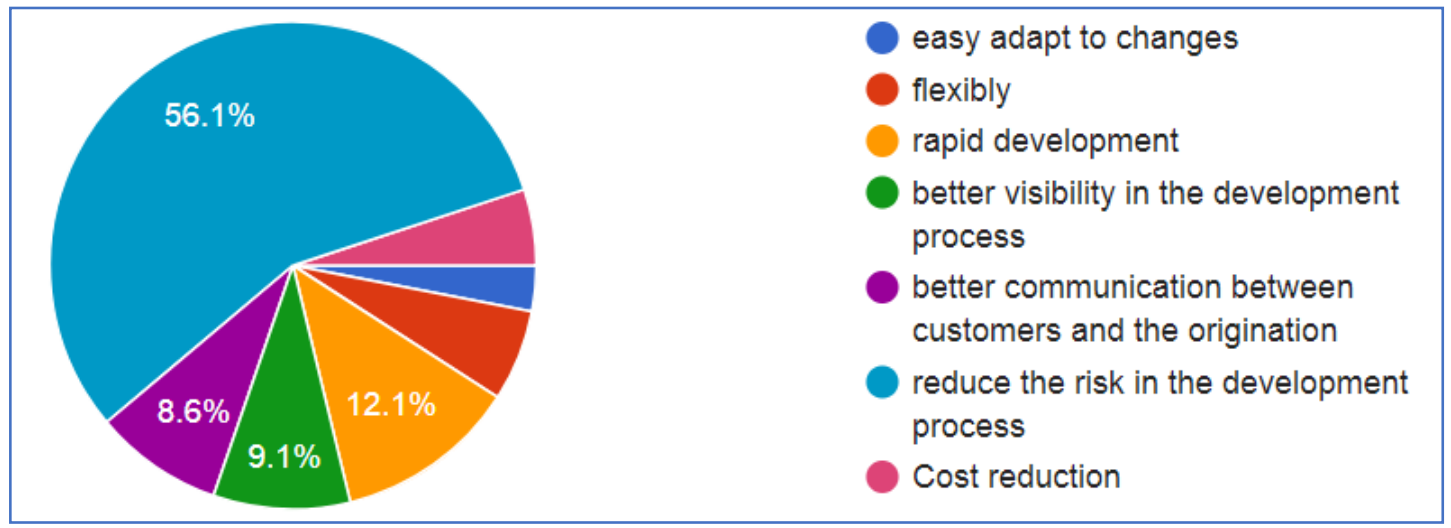

Figure 1. most benefit result that the respondents notice during use Scrum

According to the survey depicted in Figure 2, not all respondents agreed that the scrum model should be adopted by small and medium-sized businesses. Because adoption requires some pre-adoption strategies, 59 percent of respondents selected the three factors that could result in failure or success. According to our research, managers are hesitant to adopt scrum in business firms because it requires a staff with sufficient knowledge and experience from various companies to apply. Additionally, some believe that even if the company adopts the scrum model, they will fail because it will suspend some of their projects until the team demonstrates the ability and skill to complete them.

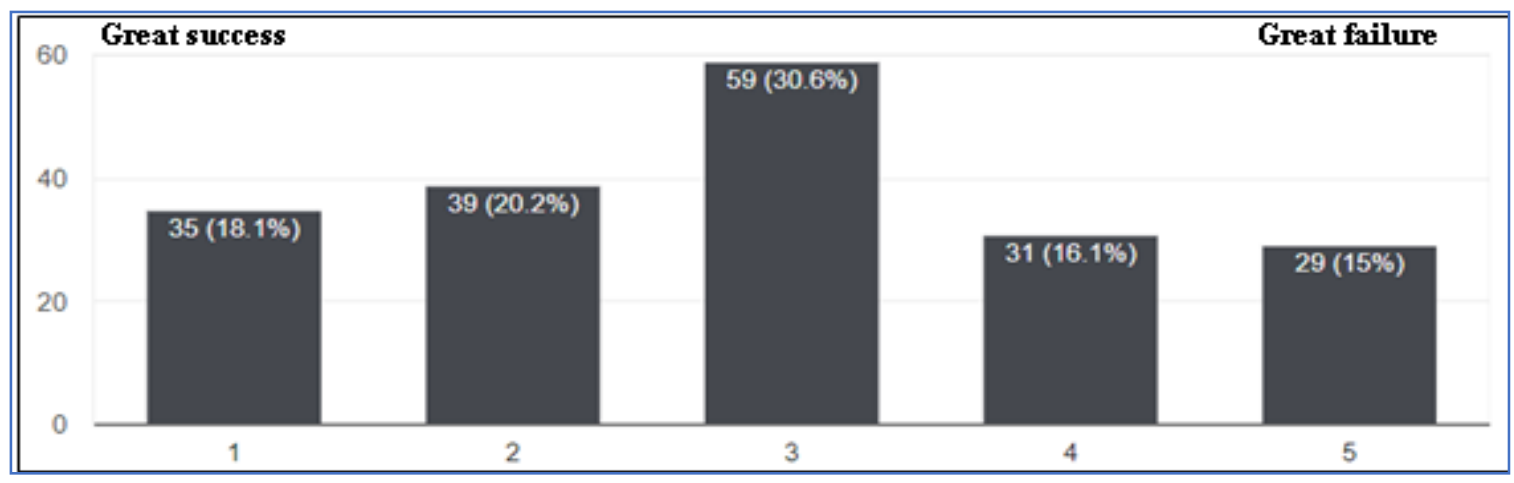

Figure 2. Rates of organizations scrum adoption programs in projects 
It is clear from our respondents' responses that they do not believe that perceived limitations associated with scrum approaches, such as a lack of formal guidelines, insufficient rewards, or an increased risk of project failure, are inhibitors of their adoption and use (see Figure 3). Rather than that, they attribute difficulties with scrum development acceptance to organizational resistance and managerial disinterest. Lack of training and peer support are also identified as challenges, adding to the view that organizational actions, at 53.3 percent, are probably the most significant impediments to the adoption and diffusion of scrum practices. Our respondents provide additional context by identifying scrum ignorance, a lack of pair programming facilities, individual resistance, and an exclusive reliance on economic evaluation criteria as additional barriers to scrum methods adoption.

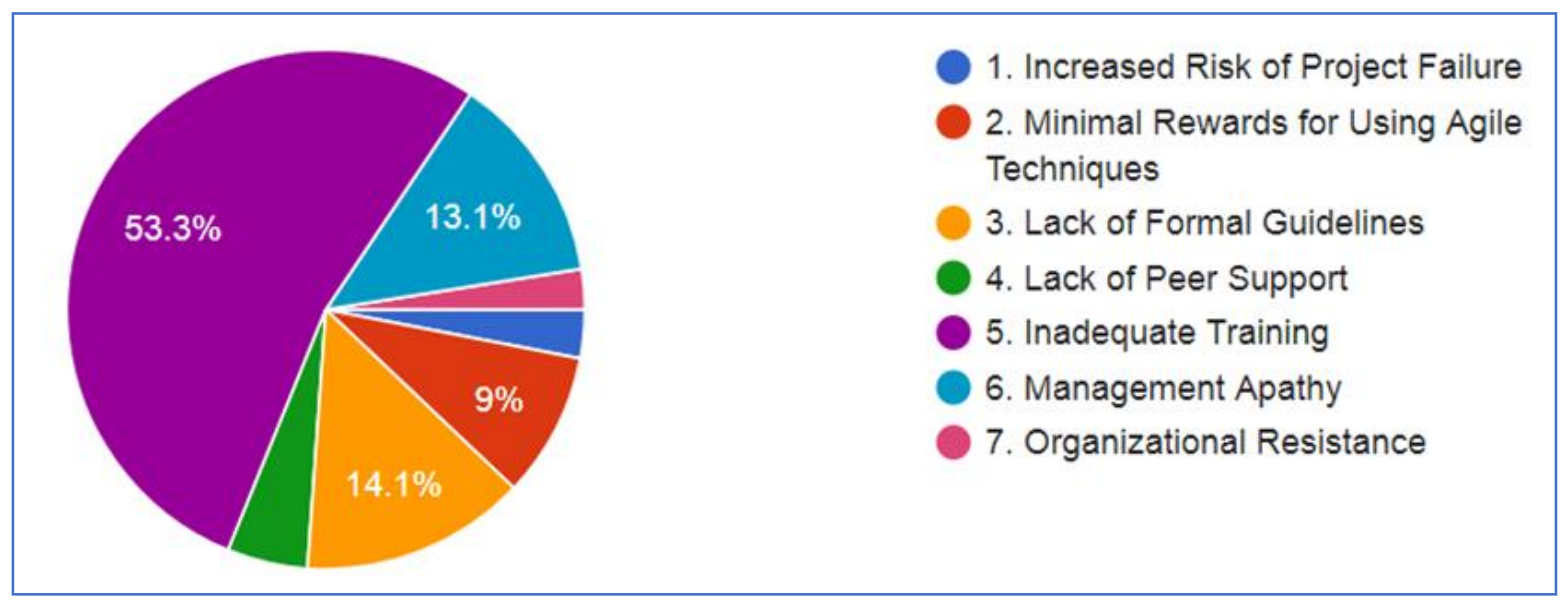

Figure 3. Problems/Challenges in the Adoption and Use of Scrum Processes and Methods in SM projects

In Figure 5, we ask respondents if their company uses any type of risk management process and discover that 70.6 percent do. The remaining 28.9 percent do not apply, as most small businesses do not survive for an extended period.

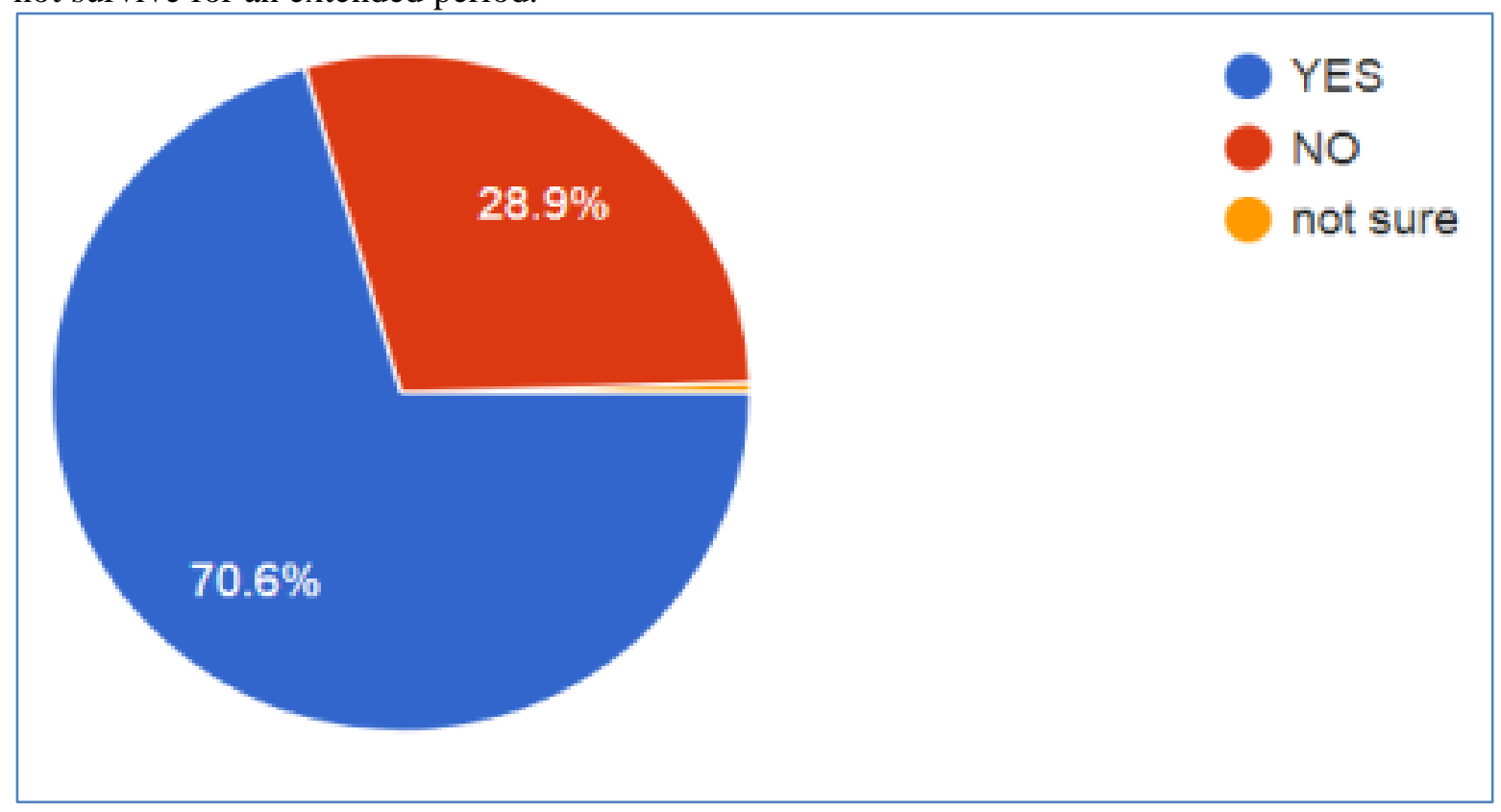

Figure 4. Working in projects that applying scrum system? 


\section{Finding}

The case, review, risk management, and evaluation of the organization were thoroughly analyzed. The researcher used Google Forms to create the survey questionnaire and took a quantitative approach. A method for compiling and interpreting the following data: 53,56 percent support scrum methods for the best business life cycle management, 70,73 percent support agile methods for risk management in small and medium-sized enterprises (SMEs).

\section{Recommendations for Further Studies}

The Figure 7 is suggested as an implication. (scrum conceptual framework secure methodology for the development of information technology) conceptual model and evaluation of information technology companies, study and development of the state of risk management processes using the scrum model, and, in exceptional cases, to serve as the context for small-scale investigations. Companies debate management strategies based on the size of their respective businesses and the role of risk management in the success of IT projects. The validity of the method design will be determined through mixed-methods or qualitative research [10]. The second approach is a structured questionnaire distributed to various project stakeholders across multiple organizations in the public sector and the information technology industry [12] [13]. Smart pls, SPSS and structural equation modelling (SEM) will be used to analyze the collected data and establish structural relationships between scrum factors.

\section{scrum conceptual framework}

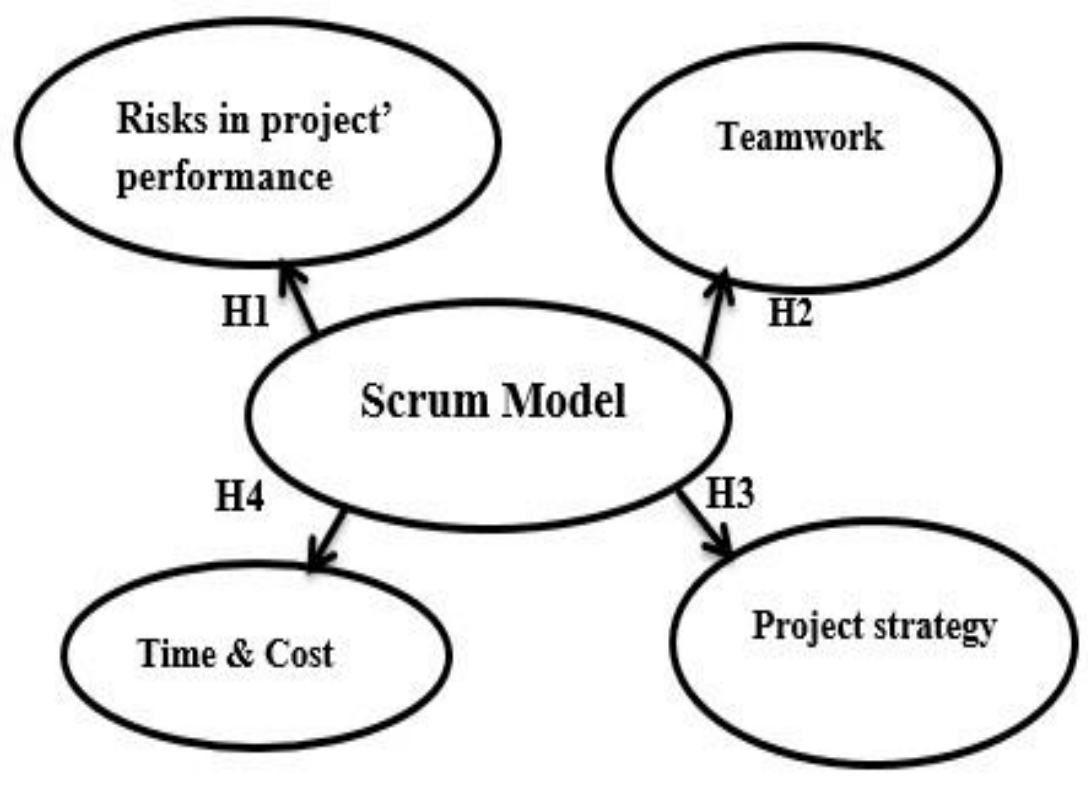

Figure 5. Scrum Conceptual Framework Secure Methodology for The Development of Information Technology [12] [14] [15]

\section{Acknowledgment}

The author wants to express his appreciation to Madam Suha Mohamed Ismail, manager, of banking for her support, as well as to Dr. Muayad Younus Amjed al-zehhawi for his aid, guidance, and advise. 


\section{Conclusions}

The results indicated that most employees are adjusting to their new scrum by working. Scheme, and the majority report feeling secure with the new system. We conduct an analysis to determine how risk management affects the scrum's performance and to determine whether risk management results in the advancement of the IT project, and if so, how it is accomplished in practice [8]. We examine field workers, comparing ideas to elicit a response.' scrum factor affecting the performance of IT projects.

\section{References}

[1] Abumandil, Mohanad SS, and Shahizan Hassan. "Information quality and decision-making effectiveness: A study of banks in Palestine." International Review of Management and Marketing 6.S7 (2016): 127-132.

[2] Beecham, Sarah, et al. "Do scaling agile frameworks address global software development risks? An empirical study." Journal of Systems and Software (2020): 110823.

[3] Chen, Edward T. "When Is It a Good Fit to Apply the Scrum Approach to Project Management." Agile Scrum Implementation and Its Long-Term Impact on Organizations. IGI Global 84-98.

[4] Esteki, Mohammad, Taghi Javdani Gandomani, and Hadi Khosravi Farsani. "A risk management framework for distributed scrum using PRINCE2 methodology." Bulletin of Electrical Engineering and Informatics 9.3 (2020): 1299-1310.

[5] Gupta, Chetna, and Priyanka Chandani. "SERIES: A Software Risk Estimator Tool Support for Requirement Risk Assessment." Advancements in Model-Driven Architecture in Software Engineering. IGI Global 238-252.

[6] Khalid, Layth Salman, and Ismail Abdul Rahman. "Measuring the Effect of the External Factors on Iraqi Construction Projects Performance USING PESTLE Technique." (2019).

[7] Khalid, Layth Salman, and Ismail Abdul Rahman. "Measuring the Effect of the External Factors on Iraqi Construction Projects Performance USING PESTLE Technique." (2019).

[8] Lei, Howard, et al. "A statistical analysis of the effects of Scrum and Kanban on software development projects." Robotics and Computer-Integrated Manufacturing 43 (2017): 59-67.

[9] LILL, PHILIPP A., ANDREAS WALD, and RONALD GLEICH. "Agility and the role of project-Internal control systems for innovation project performance." International Journal of Innovation Management 24.07 (2020): 2050064.

[10] Muayad, A. (2021). Resilient Features Of Organizational Culture In Implementation Of Smart Contract Technology Blockchain In Iraqi Gas And Oil Companies. International Journal for Quality Research, 15(2), 435-450.

[11] Muayad Younus, A. (2019,). A Model-Driven Approach to Smart Contract in Iraqi Information Technology Sector, Banking, And Insurance Companies. Journal of Emerging Technologies and Innovative Research.

[12] Muayad Younus, A. (2021). Scrum Conceptual Framework Secure Methodology for The Development of Information Technology Projects Services Of Risk Management In Malaysia. Uijir.

[13] Rahayu, Flourensia Sapty, Toni Indrawan, and Shafinah Kamarudin. "Risk Mitigation Strategies in Implementing Scrum Framework for Internet-Based IT Companies in Indonesia." Indonesian Journal of Information Systems 3.1 (2020): 50-63.

[14] Rush, Daniel E., and Amy J. Connolly. "An Agile Framework for Teaching with Scrum in the IT Project Management Classroom." Journal of Information Systems Education 31.3 (2020): 196207.

[15] Saad, Ra'ed. Developing an Agile Management Framework for Project Risk Management. Diss. The British University in Dubai (BUiD), 2020.

[16] Saad, Ra'ed. Developing an Agile Management Framework for Project Risk Management. Diss. The British University in Dubai (BUiD), 2020. 
[17] Sax, Johanna. Strategic risk management: Analyzing antecedents and contingencies for value creation. Frederiksberg: Copenhagen Business School (CBS), 2015.

[18] Sekaran, S., Foster, R. G., Lucas, R. J., \& Hankins, M. W. (2003). Calcium imaging reveals a network of intrinsically light-sensitive inner-retinal neurons. Current biology, 13(15), 1290-1298.

[19] Shafiee, Sara, et al. "Scrum versus Rational Unified Process in facing the main challenges of product configuration systems development." Journal of Systems and Software 170 (2020): 110732.

[20] Waters, Jaime. "Snowball sampling: A cautionary tale involving a study of older drug users." International Journal of Social Research Methodology 18.4 (2015): 367-380.

[21] Younus, A. M., \& Abumandil, M. (2021). Impact analysis of agile method based on risk management for developing technology management in (SMEs) Small and Medium- Enterprises. International Journal of Multidisciplinary: Applied Business and Education Research, 2(6), 493505. Retrieved from http://ijmaberjournal.org/index.php/ijmaber/article/view/133 